\title{
Short, Intermediate and Long Term Follow up of Device Closure of Atrial Septal Defect (Secundum) Cases: Thirteen Years Experience with Special Reference to Complications
}

\author{
Nurun Nahar Fatema \\ Combined Military Hospital, Dhaka
}

Key Words :

Atrial Septal

Defects, Device

closure.

\begin{abstract}
:
Background: Device closure of Atrial Septal Defect (ASD) Secundum type is gaining popularity because of short learning curve, cosmetic benefits, reduced hospital stay, reduced working hour loss, reduced pain, less or no need for general anesthesia etc. In most centers this is the first choice of therapy comparing to surgical closure. The major concern recently is related to development of erosion and aortic regurgitation. Objective of our study is to review the outcome of our cases over last 13 years with special reference to complication in our series and review from literatures.

Methods: One thousand and twenty patients with secundum ASD with indication for closure, age 8 months to (median 11 years) 68 years from December 2000 to December 2013 were included in the study. Patient were followed up after device closure at 1, 3, 6, 9, 12, and 18 months and yearly thereafter with ECG, CXR, and Echocardiography. One hundred and seventy two cases were lost from follow up after first year.

Results: Device was implanted on 1020 patient but tried on 1075 patient. Forty one cases postponed after balloon sizing and 12 for unstable position of device or mashrooming deformity of device. Immediate complications were ST changes $(n=12)$, transient arrhythmia $(n=4)$, residual shunt $(n=7)$ etc. Immediate major complication was embolization of device $(n=2)$. There was no late embolization, thromboembolic events, erosion, pericardial effusion, aortic regurgitation in follow up. Mean follow up time was 6.9 years (8 month to 13 years). Residual shunt was abolished in all patients other than those having another uncovered ASD (2 cases).
\end{abstract}

Conclusion: Device closure of ASD is safe and effective in short, intermediate and long term follow up without any major late complication.

(Cardiovasc. j. 2015; 7(2): 85-92)

\section{Introduction:}

The technique of transcatheter closure of Atrial Septal Defect (ASD) has been in evolution since the original report by King and Mills in $1976 .{ }^{1}$ Researchers are continuously working on designing various types of smooth, safe device with less chance of embolization /complication and physician/patient friendly delivery system. On the other hand physician and patient/ parents are rapidly attracted for short learning curve, cosmetic benefit, short hospital stay, less work day loss and good outcome. ${ }^{2}$

There are many studies related to immediate, intermediate and long term follow up. ${ }^{3-6}$ These studies gave emphasis on immediate procedural success, residual shunting, air embolism, thromboembolic events, device embolization, arrhythmia etc. ${ }^{7,8}$

Recently there is concern on late development of aortic erosion and regurgitation due to implantation of atrial septal defect occlusion devices. ${ }^{9-11}$ Cardiac perforation after device closure of ASD was also reported. ${ }^{11}$ There was review of registry by Zahid Amin el al. to analyze complications and prepare a recommendation to minimize future risk. ${ }^{12}$

This study will report on our experience over last 13 years on device closure of atrial septal defect with various devices and their outcome with special reference to complications.

Address of Correspondence: Prof. Nurun Nahar Fatema, Department of Paediatric Cardiology, Combined Military 
Our early experience on immediate, short and intermediate term follow up result was already published in $2004 .^{4,5}$

\section{Methods:}

All patients with feasible Atrial Septal Defect by echocardiography (Secundum type) admitted to a tertiary care hospital of Dhaka city under care of pediatric cardiologist from December 2000 to December 2013 were included in this study. All these cases were evaluated thoroughly by chest X-ray (CXR), 12 lead ECG and transthoracic echocardiography before enrollment in device closure group. Some of the adult patients were also evaluated for other co-morbid conditions like coronary artery disease, other arrhythmia, renal disease and diabetes etc.

So lipid profile, renal function, blood sugar and Holter ECG were advised in those cases. Before cardiac catheterization normal pre catheterization evaluation and blood tests were performed in all cases. (Blood CBC, PT, APTT, Urea, Creatinine, Electrolytes, HBsAg, blood grouping etc). Trans oesophageal echo was performed only in two adult cases during procedure for poor echo window. Initial inclusion criteria for patients in TTE (Trans thoracic Echo) were secundum type ASD with rim of minimum $7 \mathrm{~mm}$ in all direction. Special emphasis was given on aortic rim. Rim size less than $5 \mathrm{~mm}$ were excluded after TEE. Patient with other associated defect which is not suitable for transcatheter closure, patient with Eisenmenger change and patient with heart failure were excluded from the study.

All cases above 18 years were considered as adult and performed in awake condition with the consent of patient. Intensive care technician was always complication with the patient to give moral support and to take care of any. All the children were sedated with Injection Midazolum, Injection Ketamine, Injection Phenobarbitone either alone or as cocktail.

All the cases were done under local anaesthesia in femoral region with $1 \%$ lignocaine and sedating children up to 18 years of age. General anaesthesia was not required in any case of our series.
All the procedure was guided by both fluoroscopy and transthoracic echo (TTE). Trans oesophageal Echo (TEE) was done only in two cases with poor echo window. Echocardiography was performed by expert technician and operating cardiologist. Balloon sizing was performed in all cases except two to determine size of ASD device. Right heart hemodynamic study was performed only in cases with severe pulmonary hypertension to look for PVR and reversibility of pulmonary artery pressure. Angiographic image was not taken in 986 cases. In rest 24 cases pulmonary artery angiography was performed in initial learning stage to look for ASD in levo phase. During balloon sizing, stretched diameter and stop flow technique was used. For floppy and soft rims stop flow technique was used. In most of the cases left upper pulmonary vein technique was used for engaging wire and releasing device.

Femoral arteries were not cannulated in simple adult cases (58) as cases were considered as easy and there was good predicting factor of quick completion of cases like good sized rims, total inter atrial septum (IAS) etc.

In eight cases with very small left atrium, LA disc was partially opened inside right atrium, later pushed softly to small left atrium above inter atrial septum and then opened completely. Secure position was confirmed by tag test (push and pull maneuver). All adjacent structures like atrio ventricular valve, superior vena cava, right pulmonary vein were checked for obstruction by trans thoracic echo in all except two cases (TEE). Residual shunt and proper positioning of device on both side of atrial septum and over aortic root was examined.

All the patients were heparinized with $100 \mathrm{u} / \mathrm{kg}$ heparin during procedure. Activated clotting time was kept above 200. Injection ceftriaxone 50mg/ $\mathrm{kg}$ body weight was pushed in IV drip during procedure and continued up to 48 hours. Aspirin $5 \mathrm{mg} / \mathrm{kg}$ was advised to all patients up to 6 months. All patients were observed for 24 hours in post catheterization observation room with monitoring of ECG and all vital signs in overhead monitor. Injection Heparin was repeated 6 hours and 12 
hours after procedure. Twelve lead ECG was performed at 8 hours and 24 hours after procedure. Pressure bandage was removed next morning and CXR, and echocardiography was performed before discharge. Next follow up was advised on 1, 3, 6, 9, $12,18,24$ months and yearly thereafter. Chest Xray, ECG, and echocardiography were performed in each follow up.

All the patient attended follow up regularly up to one year, but some of the patients (172) were lost from follow up thereafter slowly because of poverty and overconfidence of complete cure after successful procedure. For tabulation and statistical significance SPSS v14, students t test and chisquared test was implied.

\section{Results:}

Total 1075 patients were enrolled for device closure. Forty one patients were excluded after balloon sizing, twelve patients had unstable position and mashrooming deformity of device and two were embolized. Six of them were children and rests were adult. Device was implanted successfully in 1020 cases (Fig - 1). In twelve cases device was taken out as position was unstable and two devices were embolized.

The age ranged from 8 months to 68 years (Median 11 years). There were 692 (67.84\%) female and 328 $(32.16 \%)$ male with ratio of 2.1:1 (Fig 2). The body weight of the patients ranged from $7 \mathrm{~kg}$ to $76 \mathrm{~kg}$ (Median $16 \mathrm{Kg}$ ).

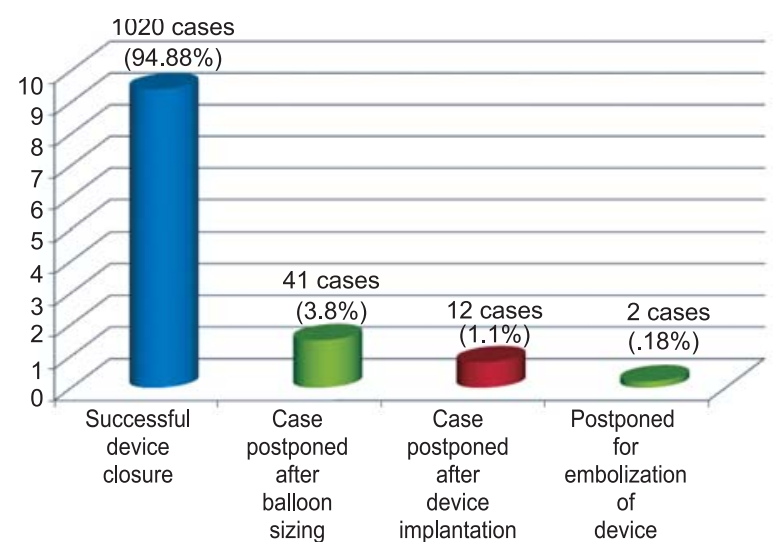

Fig.-1: Summary of patients accepted for device closure $(n=1075)$.
Table-I

Age distribution of patient (median 11 years) $(n=1020)$.

\begin{tabular}{lcc}
\hline Age & Number & Percentage \\
\hline 8 Months -5 Years & 220 & $21.57 \%$ \\
$>$ 5 Years - 10 Years & 385 & $37.74 \%$ \\
$>$ 10 Years - 20 Years & 193 & $18.83 \%$ \\
$>$ 20 Years & 222 & $21.00 \%$ \\
\hline
\end{tabular}

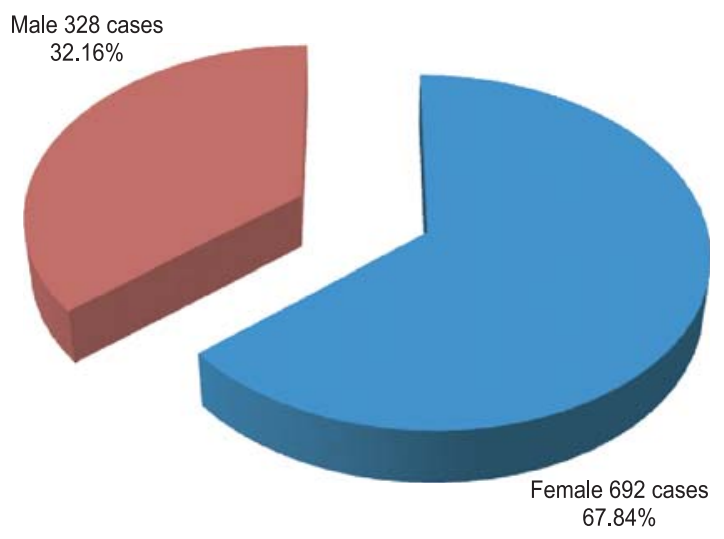

Fig.-2: Sex distribution of patient $(n=1020)$.

Defect size varied from $5 \mathrm{~mm}$ to $34 \mathrm{~mm}$ in transthoracic echocardiography, median was 24 mm (Table - II).

Table-II

ASD size measured with Transthoracic Echocardiography (TEE), (Median $24 \mathrm{~mm}$ ) $(n=1020)$.

\begin{tabular}{lcc}
\hline ASD size by TEE & Number & Percentage \\
\hline $5-10 \mathrm{~mm}$ & 38 & $3.7 \%$ \\
$>10-20 \mathrm{~mm}$ & 437 & $42.8 \%$ \\
$>20-30 \mathrm{~mm}$ & 490 & $48.0 \%$ \\
$>30-34 \mathrm{~mm}$ & 55 & $5.4 \%$ \\
\hline
\end{tabular}

Table-III showed severity of pulmonary hypertension. Normal or mild pulmonary hypertension was observed in 625 (62.25\%) cases, Moderate pulmonary hypertension was observed in $302(29.60 \%)$ cases and severe pulmonary hypertension was observed in $93(9.12 \%)$ cases. 
Table- III

Pulmonary artery pressure in study cases $(n=1020)$.

\begin{tabular}{lcc}
\hline $\begin{array}{l}\text { Pulmonary hypertension } \\
\text { status }\end{array}$ & Number & Percentage \\
\hline Mild PHT (30-40 mm Hg) & 625 & $62.25 \%$ \\
Mod PHT (40-60 mm Hg) & 302 & $29.60 \%$ \\
Severe PHT (>60 mm Hg) & 93 & $9.12 \%$ \\
\hline
\end{tabular}

Balloon stretched diameter/stop flow was achieved at $8 \mathrm{~mm}$ to $34 \mathrm{~mm}$. Device size was ranged from $10 \mathrm{~mm}$ to $40 \mathrm{~mm}$ (Median size $24 \mathrm{~mm}$ ) (Table - IV \& V).

Table-IV

$A S D$ size measured with sizing balloon of different size $(n=1020)$.

\begin{tabular}{lcccc}
\hline Balloon size & $18 \mathrm{~mm}$ & $24 \mathrm{~mm}$ & $34 \mathrm{~mm}$ & $\begin{array}{c}\text { Without } \\
\text { sizing } \\
\text { balloon }\end{array}$ \\
\hline Number & 198 & 387 & 433 & 02 \\
Percentage & $19.41 \%$ & $37.94 \%$ & $42.45 \%$ & $0.2 \%$ \\
\hline
\end{tabular}

Table-V

Size of various device used in study group, Median $26 \mathrm{~mm}(\mathrm{n}=1020)$.

\begin{tabular}{lcc}
\hline Size of device & Number & Percentage \\
\hline $10 \mathrm{~mm}$ & 12 & $1.18 \%$ \\
$12 \mathrm{~mm}$ & 26 & $2.55 \%$ \\
$14 \mathrm{~mm}$ & 56 & $5.49 \%$ \\
$16 \mathrm{~mm}$ & 104 & $10.19 \%$ \\
$18 \mathrm{~mm}$ & 127 & $12.45 \%$ \\
$20 \mathrm{~mm}$ & 108 & $10.58 \%$ \\
$22 \mathrm{~mm}$ & 70 & $3.86 \%$ \\
$24 \mathrm{~mm}$ & 83 & $8.14 \%$ \\
$26 \mathrm{~mm}$ & 49 & $4.8 \%$ \\
$30 \mathrm{~mm}$ & 83 & $8.13 \%$ \\
$32 \mathrm{~mm}$ & 74 & $7.26 \%$ \\
$34 \mathrm{~mm}$ & 76 & $7.45 \%$ \\
$36 \mathrm{~mm}$ & 72 & $7.05 \%$ \\
$38 \mathrm{~mm}$ & 12 & $1.17 \%$ \\
$40 \mathrm{~mm}$ & 02 & $0.19 \%$ \\
\hline
\end{tabular}

The procedure time varied between 16 minutes to 65 minutes (Median 35 Minutes). Fluoroscopy time varied from 3 minutes to 48 minutes (Median 10 minutes). Procedure and fluoroscopy time was longer in initial 2/3 years but with experience time reduced (Table VI).

Table-VI

Time required for ASD device closure $(n=1020)$.

\begin{tabular}{llcc}
\hline & Time (Median) & Number & Percentage \\
\hline Procedure & $15-30$ minutes & 335 & $32.84 \%$ \\
& $30-65$ minutes & 685 & $67.16 \%$ \\
& Median -35 & & \\
Fluoroscopy time & $3-30$ & 745 & $73.04 \%$ \\
& $30-50$ & 275 & $26.96 \%$ \\
& Median -10 & & \\
\hline
\end{tabular}

Immediate complete closure was achieved in 99.3\% cases. Residual shunt was observed in $0.68 \%$ cases. Embolization of device to right ventricle was experienced in $0.91 \%$ cases. Transient arrhythmia was observed in $0.39 \%$ cases. ST change due to air embolism was experienced in $1.2 \%$ cases. Ventricular tachycardia was noticed in one patient who had old myocardial infarction in right ventricle for air embolism to right coronary artery in adult catheterization laboratory during procedure of device closure of ASD. Procedure postponed on that day, patient was shifted to intensive care unit, stabilized and treated for ischemic cardiomyopathy for a year. Then device was implanted again in pediatric catheterization laboratory. He needed ICD device after one month of device closure (Table - VII). One adult case had perforation of left atrial appendage during procedure which was discovered next day as patient developed severe chest pain and respiratory distress. Review of case confirmed the fact that left atrial appendage was punctured by a cardiology trainee during trial of engaging left upper pulmonary vein. Echocardiography showed pericardial effusion. Blood was aspirated from pericardial space, Aspirin was stopped and steroid advised for three days.

Table-VII

Outcome of the study cases with complications $(n=1020)$.

\begin{tabular}{llcc}
\hline Outcome & & Number & Percentage \\
\hline Residual shunt & & 07 & $0.68 \%$ \\
Major & Embolization & 02 & $0.19 \%$ \\
complications & Pericardial effusion & 01 & $0.09 \%$ \\
& Death & 00 & 00 \\
& Major bleeding & 00 & 00 \\
& Transient & 04 & $0.39 \%$ \\
& $\begin{array}{l}\text { arrhythmia/heart } \\
\text { block }\end{array}$ & & \\
& $\begin{array}{l}\text { ST change during } \\
\text { procedure }\end{array}$ & 24 & $2.4 \%$ \\
& Ventricular & 01 & $0.09 \%$ \\
trachycardia & 00 & $00 \%$ \\
$\begin{array}{l}\text { Complete } \\
\text { heart block }\end{array}$ & & 01 & $0.09 \%$ \\
\hline Allergic reaction & & &
\end{tabular}


Major complain of patient after device closure in our study was chest pain in 96 cases (9.6\%) and allergic reaction was observed in one case only to nitinol (Table VIII).

Multiple interventions were done in some cases (Table - IX) in single setting. ASD device closure and pulmonary valvuloplasty was done in 38 (3.73\%) cases. PDA device closure was done in 6 (0.5\%) cases and VSD device closure in 15 (1.47\%) cases.

\section{Table-VIII}

Major symptoms after device closure $(n=1020)$.

\begin{tabular}{lcc}
\hline Symptom & Number & Percentage \\
\hline Chest pain & 96 & $9.6 \%$ \\
Palpitation & 53 & $4.8 \%$ \\
Allergic skin rash & 01 & $0.09 \%$ \\
Migraine headache & 04 & $0.38 \%$ \\
\hline
\end{tabular}

Table-IX

Double intervention in single setting $(n=1020)$.

\begin{tabular}{lcc}
\hline Interventions & Number & Percentage \\
\hline $\begin{array}{l}\text { ASD device closure and } \\
\text { balloon valvoplasty }\end{array}$ & 38 & $3.73 \%$ \\
$\begin{array}{l}\text { ASD device closure and } \\
\text { PDA device closure }\end{array}$ & 06 & $0.58 \%$ \\
$\begin{array}{l}\text { ASD device closure and } \\
\text { VSD device closure }\end{array}$ & 15 & $1.47 \%$ \\
\hline
\end{tabular}

Types of device used were Amplatzer 386 (37.8\%), Figulla 96 (9.42\%), Lifetech 297 (29.1\%) etc. Other Chinese and Cookon devices were used in341 (33.4\%) cases (Fig 3).

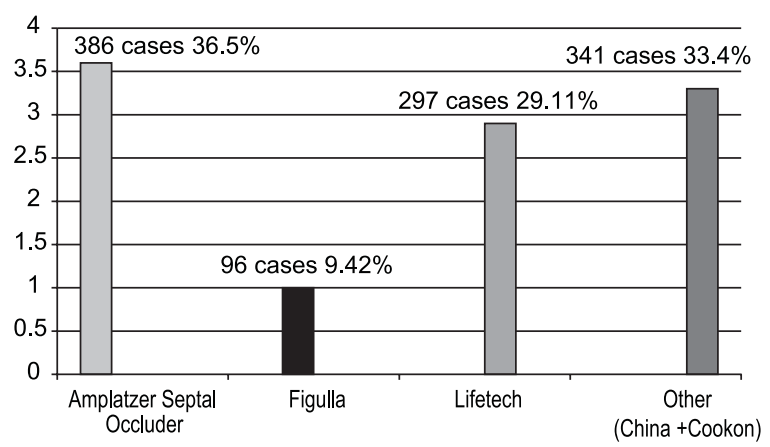

Fig.-3: Type of device used in study group ( $n=$ 1020).

\section{Discussion:}

Device closure of ASD is an attractive option both for the cardiologist and for the patient for wellknown reasons. Most important one is very high incidence $(97 \%)$ of complete closure after implantation. ${ }^{13,14}$

Reported complications so far are cardiac perforation, device malposition or embolization, residual shunt, vascular trauma, aortic erosion, aortic regurgitation, infectious endocarditis, and occasional sudden death etc. ${ }^{2,15}$

Another important complication is formation of thrombus on devices. The rate of thrombus formation on Amplatzer device is very low. ${ }^{15}$ The incidence of thrombus formation is $1.2 \%$ in ASD and $2.5 \%$ in $\mathrm{PFO}$ patients in a study of 1000 patients who underwent percutaneous device closure. Post procedural atrial fibrillation and persistent atrial septal aneurysm were significant predictors of thrombus formation. ${ }^{14}$

We used devices from six manufactures but thrombus formation was not experienced in any, though Nitinol wire of Amplatzer devices are less thrombogenic than others. Rare report of cardiac rupture and fistula formation between right and left atrium was reported in literature. ${ }^{15} \mathrm{In}$ our series we have not experienced this kind of complications. These complications are usually related to oversized devices. We cautiously avoided use of oversized device. Cases were postponed and referred to surgery in such situations.

Cheesa $\mathrm{M}$ reported on early and late complications of about 417 cases that had ASD device closure with Amplatzer (258) and cardiaoSEAL (154) devices. They encountered 36 complications in 34 cases $(8.6 \%)$. Ten patients needed surgery for embolization or malposition (1.7\%). Late complications were like embolization to left leg after one year and sudden death after 1.5 year of implantation of device. We had no late embolization in our series. Immediate embolization was $0.19 \%$. It was $2 \%$ in a study conducted in Pakistan. ${ }^{9}$ It can be emphasized that five rims must be routinely evaluated to decide before final device implantation.

Cardiac perforation is a serious complication reported in many literature. ${ }^{11.12}$ Perforation can occur during procedure and patient usually 
complaints of chest pain due to haemo pericardium, pericardial effusion or tamponade. Vulnerable sites for perforations are atrial appendages antero superior wall of atrium and adjacent aorta.

In our series one patient had cardiac perforation during manipulation of catheter to engage left upper pulmonary vein by a cardiology trainee. Device was implanted successfully but patient developed chest pain next day and pericardial effusion was detected by echocardiography.

Divekar et al. in a retrospective review found 24 events of perforation with Amplatzer devices. ${ }^{11}$ Residual shunts after ASD device closure was seen in many studies. Rao et al. found color Doppler evidence of residual shunts in $45 \%$ of patients. ${ }^{16}$ Worm et al. found residual shunt in $37 \%$ patient with sideris device. ${ }^{17}$ In Pakistani series only 3 patients had residual shunt which was resolved in long term follow up. ${ }^{9}$ In our series residual shunt was seen in $0.68 \%$ cases ( 7 patients) out of which three were due to uncovered small part of another ASD at lower end of device.

In present study no residual shunt was observed in $99.3 \%$ cases. Among residual shunt $0.7 \%$ (4) cases closed spontaneously and 3 had uncovered small additional ASD in lower end of device. All except two devices in our study were selected by balloon sizing technique. Two were selected on the basis of stretched diameter.

Cardiac erosion is another complication which may result from longer device size leading to mushrooming deformity. ${ }^{16.17}$ On the other hand smaller device leads to risk of device instability, embolization and residual shunt. ${ }^{18.19}$ So device sizing is crucial to avoid complications. In our series we had no mushrooming deformity or erosion so far. In 12 of cases devices were recaptured inside delivery system and taken out for unstable position and mashrooming deformity. In our series we strictly followed guidelines from pivotal study of Amplatzer septal occluder and Helex occluder. ${ }^{20.21} \mathrm{As}$ a result our erosion/perforation rate was very rare. Only one case had perforation during catheterization before device closure. Pivotal study of ASD also found low adverse event in device group than surgical group in a comparative study. ${ }^{20.21}$

MAGIC Study (2004 - 2007), reported the results of multi institution use of ASO in 478 patients showed major adverse event rate of $1.1 \%$.

A retrospective review of the all adverse events reported to the FDA manufacturer and user facility device experience (MAUDE database) published in the literature included a review of institutional cases by Divekar et al in 2005 found total 24 cases of cardiac perforation. ${ }^{11}$

MUADE database found 21 (0.62\%) embolization in 3,824 cases of ASO implants in the study group. There were 2 death related to embolization. Fifteen devices were retrieved by snare catheter and 6 retrieved surgically. In our study two embolization happened due to floppy aortic rim. One was retrieved with snare and another retrieved surgically.

Amin et al. in 2004 determined the erosion rate to be nine in 9000 US implants group giving a rate of 0.1 percent. Erosion is found to be reported as late as 3 to 5 years after deployment. In our series we have no erosion so far in follow up. Our first case is under follow up for 14 years now.

A more recent meta analysis of currently available clinical evidence on percutaneous versus surgical closure of ASD was performed by Butera et al (total 3082 cases, 1270 had surgical closure and 1812 had device closure). ${ }^{23}$ Major complication rate was $1.9 \%$ in device group and $6.8 \%$ in surgical group. ${ }^{23}$ After reviewing many relevant literature we found some useful recommendations from expert panel ${ }^{16}$.

1) Instruction for use should be followed during balloon sizing.

2) Overstretching of balloon should be avoided.

3) Stop flow technique should be followed during balloon sizing.

4) Gentle maneuver during to and fro movement while checking device stability.

5) Close follow up of below category patients.
a) Larger ASO used (>1.5 times of ASD).
b) Who developed pericardial effusion.
c) Those with deformed ASD device.
d) Those with high up defects.

In order to better understand factors causing device erosion, a survey was conducted by congenital cardiovascular interventional study consortium (CCISE). Following are the recommendations of expert in $2004 .^{16}$ 
1) Deficient aortic rim is the cause of erosion in $90 \%$ cases.

2) Device with lower risk of erosion are those which straddle the aorta, are somewhat oversized and do not move relative to heart.

3) Device with higher risk are those with protruding left atrial disc on aortic root, somewhat undersized and many have motion related to heart structure.

In our series we used devices from six different manufacturers but no difference in complication pattern was noticed so far as manufacturer company concern. Our major complications were related to floppy rim (embolization) in two cases and perforation of left atrial appendage by catheter tip in one case before starting proper device procedure. It was detected on next day when patient complained of chest pain.

\section{Conclusion:}

We performed first case in our center in the year 2000. We experienced embolization in only two cases. There was no record of any unexplained death in study group. One of our patients died from drowning in village home one year after procedure. So transcatheter closure of ASD is safe, effective and acceptable option for patient with secundum ASD. Balloon sizing of ASD was a safe option to measure device size and trans thoracic echo was found as good option in children than trans esophageal Echo.

\section{Conflict of Interest - None.}

\section{References:}

1. King TD, Mills NL. Secundum Atrial Septal Defects: Non operative closure during cardiac catheterization. JAMA 1976; 235: 2506 - 2509.

2. Di Bardino DJ, McElhinney DB, Kaza AK et al. Device experience database for adverse events involving Amplatzer Septal Occluder devices and comparison with the society of Thoracic Surgery and Congenital Cardiac Surgery data base. Analysis of the US food and Drug Administration Manufacturer and user facility. $J$ Thorac Cardiov Sur 2009; 137(6):1334- 1341.

3. Chessa M, Camusiraty M, Butera G, Bini RM, Drago M, Rosi L et al. Early and late complications associated with transcatheter occlusion of secundum Atrial Septal Defect. J Am Coll Cardiol 2002;39: 1061-1065.
4. N.N.Fatema, S.M Rahman, M.R.karim, Z Khan. Immediate, short and intermediate term outcome of transcatheter secundum ASD closure: Analysis of thirty one cases. JAFMC 2005; 1(1): 7-11.

5. N.N.Fatema, Q.S.Ahmed, S.M.Rahman. Transcatheter closure of Atrial Septal Defect: Early clinical experience in children of Bangladesh. Chest and Heart Journal 2004;28(2):46-49.

6. Latson LA, Benson LN, Hellenbrand WE, Mullins CE, Lock JE. Trans catheter closure of ASD early results of multicenter trial of the Bard - Clamshell Septal Occluder. Circulation 1991;84:544.

7. Berger F, Ewert P, B jornstad PG, Dahnert I, Kring G, Brilla Austenat et al. Trans catheter closure as standard treatment for most inter atrial defects: Experienced in 200 patients treated with the Amplatzer septal occluder. Cardiol Young 1999; 9(1); 468-473.

8. Rao PS, Sideris EB, Housdorf G, Rey C, Lioyd Tr, Beekman $\mathrm{RH}$ et al. International experience with secundum atrial septal defect occlusion by buttoned device. Am Heart J 1994; 128: 1022-1035.

9. Tehurina Kazuni, Masood Sadiq, A. Rahman, N. Haider, F. Latif. J Ayub Med Coll Abbottabad 2009; 21(3): 117-121.

10. U.S. Food and Drug Administration Website. http:// www.fdagov/default.htm

11. Divekar A, Gaamangwe T, Shaikh N, Raabe M, Ducas J. Cardiac perforation after device closure of atrial septal defects with Amplatzer septal occluder. J Am Coll Cardiol 2005; 45: 1203-1208.

12. Amiz Z, Hijazi ZM, Bass JL, Cheathum JP, Hellebrand WE, Kleinmar CS. Erosion of Amplatzer Septal Occluder device after closure of secundum Atrial Septal Defect: Review of registry of complications and recommendation to minimize future risk. Catheter Cardiovasc Interv 2004;63(4):496-502.

13. Marc D, Knepp, Albert P, Rouhini, Thomas LIoyd, Ranjit M Aiyagari. Long term follow up of Secundum Atrial septal defect closure with the Amplatzer Septal Occluder. Congenit Heart Dis 2012;5:32-37.

14. Rania BH, Magdi Kh, Al Gaarash. Selection of device size for Atrial Septal Defect closure using Transesophageal Echocardiography without Balloon sizing: Experience at Queen Alia heart Institute. JRMS 2013; 20(4):19-23.

15. Krumsdorf U, Ostermayer S, Billinger K. Incidence and clinical course of thrombus formation on atrial septal defect and patent foramen ovale closure devices in 1000 consecutive patients. J Am Coll Cardiol 2004;43(3):302-309. 
16. Amin Z, Hizazi Z M, Bass JL. Erosion at secundum atrial septal defects: Review of registry of complications and recommendations to minimize future risk. Catheter Cardiovasc Interv 2004; 63:496-502.

17. Divekar A, Gaamaagwe T, Shaikh N. Cardiac perforation after device closure at atrial septal defects with the Amplatzer Septal Occluder. J Am Coll Cardiol $2005 ; 45: 1213-1218$.

18. Levi DS, Moore JW. Embolization and retrieval of the Amplatzer Septal Occluder. Catheter Cardiovasc Interv 2004;61: 543-571.

19. Zanchetta M, Onorato E, Rigatelli G. Intracardiac Echocardiography guided trans catheter closure of secundum atrial septal defect. J Am Coll Cardiol 2003; 42:1677-1682.
20. AGA Medical Corporation. Amplatzer Septal Occluder: http: //www. fda/gov/ohrms /dockets/ac/01/briefing/379/ ob1-01-sponsor.pdf.

21. Gore Medical: Gore ${ }^{\circledR}$ Helex ${ }^{\circledast}$ septal occluder..http:// www.gore medical.com/Helex/instruction.

22. Everest AD, Jennings J, Sibinga E, Owada C, Lim DS, Cheatham et al. Community use of the Amplatzer Atrial Septal Defect Occluder : Results of the multicenter MAGIC Atrial Septal Defect study. Pediatric Cardiol 2009; 30(3): 240-247.

23. Butera G,Biondi-Zoccai G, Carminati M , Abella R, Giambrati A, Bussadori C, Sheban I et al. Percutaneous versus surgical closure of secundrum atrial septal defect: A systematic review and meta analysis of currently available clinical evidence. Eurointervention 2011;7 (3): 377-385. 